\title{
Cognitive predictors of balance in Parkinson's disease
}

\author{
Ângela Fernandes ${ }^{\mathrm{a}, \mathrm{b}}$, Andreia Mendes ${ }^{\mathrm{c}}$, Nuno Rocha ${ }^{\mathrm{a}}$ and João Manuel R. S. Tavares ${ }^{\mathrm{d}}$ \\ a Escola Superior da Tecnologia de Saúde do Instituto Politécnico do Porto, Área Científica de Terapia Ocupacional, Centro de Estudos de \\ Movimento e Actividade Humana, Vila Nova de Gaia, Portugal; ${ }^{b}$ Faculdade de Engenharia, Universidade do Porto, Porto, Portugal; ${ }^{\mathrm{c} E s c o l a}$ \\ Superior da Tecnologia de Saúde do Instituto Politécnico do Porto, Área Científica de Física, Centro de Estudos de Movimento e Actividade \\ Humana, Vila Nova de Gaia, Portugal; 'Instituto de Ciência e Inovação em Engenharia Mecânica e Engenharia Industrial, Departamento de \\ Engenharia Mecânica, Faculdade de Engenharia, Universidade do Porto, Porto, Portugal
}

\begin{abstract}
Postural instability is one of the most incapacitating symptoms of Parkinson's disease (PD) and appears to be related to cognitive deficits. This study aims to determine the cognitive factors that can predict deficits in static and dynamic balance in individuals with PD. A sociodemographic questionnaire characterized 52 individuals with PD for this work. The Trail Making Test, Rule Shift Cards Test, and Digit Span Test assessed the executive functions. The static balance was assessed using a plantar pressure platform, and dynamic balance was based on the Timed Up and Go Test. The results were statistically analysed using SPSS Statistics software through linear regression analysis. The results show that a statistically significant model based on cognitive outcomes was able to explain the variance of motor variables. Also, the explanatory value of the model tended to increase with the addition of individual and clinical variables, although the resulting model was not statistically significant The model explained $25-29 \%$ of the variability of the Timed Up and Go Test, while for the anteroposterior displacement it was $23-34 \%$, and for the mediolateral displacement it was $24-39 \%$. From the findings, we conclude that the cognitive performance, especially the executive functions, is a predictor of balance deficit in individuals with PD.
\end{abstract}

\author{
KEYWORDS \\ Parkinson; balance; \\ cognition; predictors; \\ displacement
}

\section{Introduction}

Parkinson's disease (PD) is a chronic and progressive neurodegenerative disease that affects $41 / 100000$ in 40 - to 49-yearolds and 1903/100 000 in persons over 80 years old (Pringsheim et al. 2014).

Several studies have reported cognitive impairments in PD (Williams-Gray et al. 2007; Merims and Freedman 2008; Koerts et al. 2009, 2011; Aarsland et al. 2011), even at early stages of the disease (Elgh et al. 2009; Aarsland et al. 2011; Pagonabarraga and Kulisevsky 2012). In PD, deficits are common in executive functions (EFs) (Coppin et al. 2006). EFs can be defined as cognitive competences that facilitate the successful completion of activities in an independent and intentional manner and with the appropriate behaviour (Lezak et al. 2004). Examples include inhibition of automated responses, recovery from declarative memory, planning, monitoring, cognitive flexibility, and the maintenance of information in the working memory (Schwarz and Shapiro 1986). Cognitive impairments can have a significant negative influence on carrying out daily life activities and are associated with a lower quality of life (Klepac et al. 2008).

The cognitive processes have an important role that increases with age and they should be preserved to ensure a good postural control (Jamet et al. 2007). Recent studies have shown that impairments in EFs are closely related to motor symptoms, particularly with postural instability (Lindholm et al. 2014). This may be due to the important role of these functions in anticipation, planning, and coordination (McCloskey and Perkins 2012). Research suggests that abnormal displacements of the centre of pressure are related to balance deficits and consequently, they lead to the occurrence of falls in about $51-68 \%$ of individuals with PD. In addition, the duration of illness, fear of falling, and cognitive changes were also related to balance deficits, thereby contributing to the independent risk factors for falls (Matinolli et al. 2007).

Individuals with PD frequently use cognitive strategies to maintain balance and postural stability due to their deficits in terms of automaticity (Smithson et al. 1998). However, the studies found that cognitive deficits in PD do not establish a relationship between the dynamic and static balance and the different EFs. Thus, the aim of this study was to define that relationship by identifying the predictors of balance deficit in individuals with PD.

\section{Material and methods}

\section{Study design}

A cross-sectional study was designed using a non-probabilistic sample of 52 individuals with PD. The individuals diagnosed with PD were from an outpatient department for movement disorders of a hospital in Portugal. A total of 62 
Table 1. Characterization of the sample studied.

\begin{tabular}{lcc}
\hline Sample $(n=52)$ & Mean (SD) & Range \\
\hline Age (years) & $67.3(8.9)$ & $39-83$ \\
Parkinson's disease (years) & $7.9(5.5)$ & $1-23$ \\
Weight $(\mathrm{kg})$ & $72.3(13.1)$ & $52-103.8$ \\
Height $(\mathrm{cm})$ & $165(8.3)$ & $145-182$ \\
Gender-male, $n(\%)$ & $33(63.5)$ & \\
\hline
\end{tabular}

$\mathrm{SD}=$ standard deviation.

individuals with PD were initially assessed; however, 10 individuals were excluded: 5 for having severe cognitive impairment, 2 due to subthalamic surgery, and 3 that could not walk without assistance. Table 1 shows that the sample studied had an average age of $67.3( \pm 8.9)$ years old and the mean duration of the disease was $7.9( \pm 5.5)$ years. The average weight of the individuals was $72.3 \mathrm{~kg}( \pm 13.1)$, and their average height was $165( \pm 8.3) \mathrm{cm}$.

The patients evaluated here were being treated for movement disorders at an outpatient department of a hospital and had been referred by a neurologist based on the score of the Modified Hoehn and Yahr Scale. All individuals voluntary agreed to participate in this study. The inclusion criteria were: capacity to walk $10 \mathrm{~m}$ without gait assistance and diagnosis of PD up to Stage 3 according to the Modified Hoehn and Yahr Scale (Hoehn and Yahr 1967); and the exclusion criteria were: (1) the presence of a severe cognitive impairment, screened using the Mini Mental State Examination (MMSE) test (Folstein et al. 1975); (2) diagnosis of other neuromuscular diseases; and (3) history of deep brain stimulation through subthalamic surgery. All participants had good vision; although some of them used glasses. A trained researcher conducted the data collection using a structured protocol.

The Ethical Review Boards of the institution involved approved this study and each participant signed a written informed consent, according to the Helsinki Declaration.

\section{Instruments}

The data collected from all participants included sociodemographic characteristics and the severity of the motor function impairments based on the Hoehn and Yahr Scale and part III of the Unified Parkinson's Disease Rating Scale (UPDRS-III) (Goetz 2003). UPDRS assesses the signs, symptoms, and perception of individuals concerning their performance of activities of daily living (ADLs), based on a self-report and clinical observations. Here, only the motor exploration (UPDRS-III) was applied; the score of each item varies between 0 and 4, from normal to severe, respectively, and the total score of UPDRSIII ranges from 0 to 52 . This scale is often accompanied by the Modified Hoehn and Yahr Scale (Hoehn and Yahr 1967), which evaluates the severity of overall dysfunction in individuals with PD. The scale increases with the severity of the dysfunction along with the stage of the disease. The MMSE test was used adopting the following cut-offs: $\leq 22$ for $0-2$ years of formal education, $\leq 24$ for $3-6$ years, and $\leq 27$ for $\geq 7$ years, which are based on the normative values for older Portuguese adults (Morgado et al. 2009), as the exam performance varies within a population according to their educational level.
The EFs were also assessed. The Rule Shift Cards Test (RSCardsT) is commonly used to evaluate perseverance trends and the ability to switch from one pattern to another, by taking into account the errors and the time taken to complete the task involved. The performance profile is indexed to a score based on the number of errors and total time to complete the test (Golden et al. 2000; Wilson et al. 2003). The Trail Making Test (TMT) (Reitan 1992) is a test divided into two parts: part A (TMTA) evaluates attention and processing speed, and involves sequential linking of numbers from 1 to 25, verbally; and part B (TMTB) that assesses the cognitive flexibility and sequential alternation. In each part, the final score is the total time needed to complete the task (Reitan 1992). The Digit Span Test is a sub-test of both the Wechsler Adult Intelligence Scale and the Wechsler Adult Memory Scale that measures the attention, working memory, and sequential processing. In this test, the individuals are required to organize and repeat a series of numbers that have been verbally specified. The first task is to arrange the numbers in direct order with a total of 16 trials, grouped in eight levels, wherein the amount of numbers specified progressively increases from level to level, the first of which consists of two numbers and the last one of nine numbers. At each level, the individual must verbalize correctly at least one of the sequences in order to move on to the next level. The second task of the test is similar, but the goal is to arrange the numbers in reverse order (Ostrosky-Solís and Lozano 2006).

An EMED plantar pressure platform, model AT 25A, from Novel (Munich, Germany), with a sensory area of $380 \times 240 \mathrm{~mm}^{2}$ and resolution equal to 2 sensors $/ \mathrm{cm}^{2}$ was used to evaluate the static balance. The pressure values and stabilometric measurements, such as the ones based on the centre of pressure (Putti et al. 2008; Maetzler et al. 2010), were acquired with this device at $25 \mathrm{~Hz}$.

The participants were instructed to stand on the platform and adopt a self-selected comfortable upright position. Then, the participants were instructed to remain standing on the platform and look towards a fixed point at a distance of $2 \mathrm{~m}$ for $60 \mathrm{~s}$ with their eyes open (Ebersbach and Gunkel 2011). The Timed Up and Go Test (TUG), which measures the functional mobility, was employed to assess the dynamic balance. This test was used to assess the time each individual took to get up from a chair, walk $3 \mathrm{~m}$, and return to the same chair (the total distance walked was $6 \mathrm{~m}$ ) and sit down again. The shortest time of three trails was considered the best and therefore was used in the results (Podsiadlo and Richardson 1991). The test-retest reliability and inter-rater reliability were ICC $=0.80$ and $r=0.99$, respectively (Lim et al. 2005).

All tests were carried out with the individuals taking their prescribed medication, and were therefore denoted as "ON" medication, as in other studies (Conradsson et al. 2012; Kelly et al. 2012).

\section{Statistical analysis}

Descriptive statistical analysis took into account proportions, and measures of central tendency and dispersion, according to the nature of the variables. 
Linear regressions were conducted in order to investigate the relationship between two or more variables and if one can be predicted from the other(s). Two-tailed tests were applied to all analyses and a value of $p<0.05$ was considered statistically significant. The statistical analyses were conducted in SPSS Statistics software, version 22.0 from SPSS (Chicago, IL, USA).

\section{Results}

Table 2 shows that most of the individuals (51.9\%) were classified in Stage 2 of the Modified Hoehn and Yahr Scale, and the sample had a mean UPDRS-III score of 18.8 (SD =7.9). In terms of educational levels, $65.4 \%$ had only 4 years of schooling. The majority of the individuals $(55.8 \%)$ had not suffered any falls during the last year.

After checking the correlations among the variables, linear regression analysis was adopted for modelling and to find if there were any possible significant relationships (Table 3 ). The analysis performed revealed that $25 \%$ of the variability found for the TUG was explained by the variables included in the model built with the cognitive outcomes. In this case, the TMTA was the only cognitive outcome that was found to be statistically significant by itself $(p=0.02, r=0.33)$. The cognitive outcomes explained $23 \%$ of the variability verified for the anteroposterior displacement, and the digit span forward score was the cognitive outcome that was found to be statistically significant $(p=0.03, r=-0.32)$. As for the mediolateral displacement, the cognitive outcomes explained $24 \%$ of its variability. In this case, the TMTA was the cognitive outcome that was found to be statistically significant $(p=0.03, r=$ $-0.30)$. After these results, the individual variables, like age, weight, height, body mass index, and education, and the clinical variables, such as aids, falls, years of disease, and severity were added to the model. With these additional variables, the

Table 2. Number of falls and clinical variables for the sample studied.

Sample $(n=52)$

Falls, $n(\%)$

0

$\geq 1$

Disease severity, $n(\%)$

Stage 1: Unilateral disease

Stage 1.5: Unilateral plus axial involvement

Stage 2: Bilateral disease, without impairment of balance

Stage 2.5: Mild bilateral disease, with recovery on pull test

Stage 3: Mild to moderate bilateral disease; physically independent 4 (7.7) UPDRS-III, mean (SD)

$\mathrm{SD}=$ standard deviation. analysis revealed that the variability increased to $29 \%$ in TUG, $34 \%$ in anteroposterior displacement, and 39\% in mediolateral displacement, but the resulting model was not statistically significant.

\section{Discussion}

A statistically significant model composed of cognitive outcomes was able to explain the variances of the TUG, anteroposterior, and mediolateral displacements. Also, the explanatory value of the model tended to increase with the addition of individual and clinical variables, although the resulting model was not statistically significant. This means that the individual and clinical variables have no significant influence on the motor variables. The model explained $25-29 \%$ of the variability of the TUG, while for the anteroposterior displacement it was $23-34 \%$, and for the mediolateral displacement it was $24-39 \%$.

Although PD affects primarily motor skills, an increasingly emphasis has been given to the cognitive impairment in this disease (Chaudhuri et al. 2006). Several studies have also reported cognitive changes in $\mathrm{PD}$, even in the early stages of the disease (Merims and Freedman 2008; Elgh et al. 2009; Aarsland et al. 2011; Koerts et al. 2011; Pagonabarraga and Kulisevsky 2012). It is commonly accepted that approximately $30-40 \%$ of the individuals with PD tend to develop dementia, but some studies indicate that this possibility can vary from 10 to $80 \%$ (Aarsland et al. 2005; Aarsland and Kurz 2010). Even in cases of early diagnosis of PD, the cognitive decline is about $36 \%$ (Foltynie et al. 2004). In PD, deficits in several cognitive domains, especially with respect to EFs, are common (Coppin et al. 2006). In addition, Andersson et al. (2003) concluded that postural control and cognition are not independent systems. This may be due to the important role of EFs in anticipation, planning, and motor coordination (McCloskey and Perkins 2012).

Based on the close relationship that appears to exist among postural control and cognitive and individual aspects, our linear regression analysis revealed that $25 \%$ of the variability found for TUG was explained by cognitive outcomes, increasing to $29 \%$ when the individual and clinical variables were added. In fact, studies have suggested that for good functional mobility, the individuals need to integrate cognitive components such as psychomotor speed, visual-spatial orientation, attention, and working memory (Springer et al. 2006; Van-Lersel et al. 2008).

Table 3. Regression analyses among the Timed Up and Go Test (TUG), anteroposterior, and mediolateral displacements and related variables.

\begin{tabular}{|c|c|c|c|c|c|c|c|c|c|}
\hline & \multicolumn{3}{|c|}{ TUG } & \multicolumn{3}{|c|}{ Anteroposterior displacement } & \multicolumn{3}{|c|}{ Mediolateral displacement } \\
\hline & $b$ & $95 \%$ IC & $p$ & $b$ & $95 \%$ IC & $p$ & $b$ & $95 \%$ IC & $p$ \\
\hline RSCardsT & 0.77 & ]$-0.91 ; 2.45[$ & 0.36 & -0.30 & ]$-0.61 ; 0.01[$ & 0.06 & -0.06 & ]$-0.25 ; 0.13[$ & 0.51 \\
\hline TMTA & 0.05 & ]0.01;0.09[ & 0.02 & -0.01 & ]$-0.01 ; 0.01[$ & 0.89 & 0.01 & ]0.00;0.01[ & 0.04 \\
\hline TMTB & -0.02 & ]$-0.05 ; 0.01[$ & 0.19 & -0.01 & ]$-0.10 ; 0.01[$ & 0.17 & -0.01 & ]$-0.01 ; 0.01[$ & 0.11 \\
\hline MMSE & -0.77 & ]$-1.78 ; 0.24[$ & 0.13 & 0.11 & ]$-0.07 ; 0.30[$ & 0.23 & 0.10 & ]$-0.15 ; 0.21[$ & 0.09 \\
\hline Digit Span Forward & -0.21 & ]$-1.09 ; 0.67[$ & 0.64 & -0.18 & ]$-0.34 ;-0.02[$ & 0.03 & -0.03 & ]$-0.13 ; 0.07[$ & 0.56 \\
\hline Digit Span Backward & -0.04 & ]$-1.10 ; 1.02[$ & 0.94 & -0.12 & ]$-0.31 ; 0.08[$ & 0.23 & -0.12 & ]$-0.24 ; 0.01[$ & 0.06 \\
\hline$R^{2}(p)$ & \multicolumn{3}{|c|}{$0.25(0.03)$} & \multicolumn{3}{|c|}{$0.23(0.05)$} & \multicolumn{2}{|c|}{$0.24(0.04)$} & \\
\hline
\end{tabular}

RSCardsT = Rule Shift Cards Test; TMTA $=$ Trail Making Test part A; TMTB = Trail Making Test part B; MMSE $=$ Mini Mental State Examination; $b=$ regression coefficient; $95 \% \mathrm{IC}=$ confidence interval of $95 \% ; R^{2}=$ coefficient of determination; $p=p$-value (significant values are in bold $(p<0.05)$ ). 
Concerning the static balance, the variables included led to a statistically significant model that explained $23 \%$ of the variability of the anteroposterior displacement and $24 \%$ of the variability of the mediolateral displacement, which increased to 34 and 39\%, respectively, with the addition of the individual and clinical variables. As to the anteroposterior displacement, the cognitive variables included explained $23 \%$ of the variability of the anteroposterior displacement, increasing to $34 \%$ when the individual and clinical variables were added. A recent study (Lindholm et al. 2014) has shown that cognitive impairments, particularly EFs, are closely related to motor symptoms, especially with postural instability. Hence, the results of the correlations found showed that at least one cognitive test was correlated with balance.

For the TUG and the mediolateral displacement, the TMTA was found to be the only statistically significant variable by itself ( $p=0.02$ and 0.04 , respectively), thus revealing that it can be used as a balance predictor. Physiological studies have provided evidence that the primary motor cortex reflects some aspects of sensory information to guide the motor behaviour. Additionally, the time spent in performing tasks, generally reflects the performance in terms of speed and accuracy. The speed is influenced by the degree of accuracy or insistence on accuracy to reduce error rates, which could result in increased reaction times (Sawamoto et al. 2002).

For the anteroposterior displacement, the Digit Span Test was found to be the only statistically significant variable $(p=0.03)$, and that can also be used as a balance predictor. Andrade et al. (2011) concluded that the deterioration in working memory and attention affects balance. In PD, the loss of dopaminergic neurons affects the connection between the basal ganglia and frontal cortex, which interrupts the normal flow of information through these channels, and thus affects the cognitive processes dependent on these areas (Owen 2004; Drag et al. 2009). However, PD patients rely heavily on these cortical mechanisms to carry out movements, due to the deficient function of the basal ganglia (Plotnick et al. 2009). Bond and Morris (2000) reported that individuals with PD probably have central processing resources preserved, but the basal ganglia injury means that there is a flaw in the usual shift of attention. So attentional impairments lead to a worsening of balance performance (Marchese et al. 2003).

This work should be seen as an exploratory study with limitations similar to those in other works published in the literature, particularly in terms of the size of the studied sample and the number and type of the assessment tests used. The lack of specific information about gait can be seen as a limitation; however, it should be noted that the mean UPDRS-III score of 18.8 found in the studied sample indicates a good motor performance and a reduced impact of motor performance in assessment of cognitive outcomes. Despite the limitations, the findings in this study enrich our knowledge concerning the relation between cognition and dynamic and static balance in individuals with PD.

The assessment of anxiety and depression could be of particular interest in future studies, since these disorders have a great impact on cognitive outcomes. In addition, the study of other cognitive outcomes and their impact on the motor performance could be important to understand the relationship between cognition and motor performance more precisely.

\section{Conclusion}

There are cognitive components that can be assumed as predictors of balance in PD. Here, the scores obtained for the TMTA variable and for the Digit Span Test were those that achieved the greatest statistical significance. Also, the cognitive components such as the psychomotor speed, visual-spatial orientation, attention, and working memory were shown to be the most relevant aspects with regard to the prediction of balance deficits. Moreover, the individual variables proved to have more impact on the static balance than on the dynamic balance.

\section{Acknowledgements}

The authors gratefully acknowledge the funding of Project NORTE-010145-FEDER-000022-SciTech-Science and Technology for Competitive and Sustainable Industries, co-financed by "Programa Operacional Regional do Norte" (NORTE2020), through "Fundo Europeu de Desenvolvimento Regional" (FEDER).

\section{Disclosure statement}

The authors report no conflicts of interest. The authors alone are responsible for the content and writing of the paper.

\section{References}

Aarsland D, Zaccai J, Brayne C. 2005. A systematic review of prevalence studies of dementia in Parkinson's disease. Mov Disord 20:1255-1263.

Aarsland D, Kurz MW. 2010. The epidemiology of dementia associated with Parkinson disease. J Int Neuropsychol Soc 289:18-22.

Aarsland D, Bronnick K, Fladby T. 2011. Mild cognitive impairment in Parkinson's disease. Curr Neurol Neurosci Reports 11(4):371-378.

Andersson G, Hagman J, Talianzadeh R, Svedberg A, Larsen H. 2003. Dualtask study of cognitive and postural interference in patients with vestibular disorders. Otol Neurotol 24:289-293.

Andrade L, Stella F, Barbieri F, Rinaldi N, Hamanaka A, Gobbi LTB. 2011. Efeitos de tarefas cognitivas no controle postural de idosos: Uma revisão sistemática. Motricidade $7(3)$.

Bond J, Morris M. 2000. Goal-directed secondary motor tasks: Their effects on gait in subjects with Parkinson disease. Arch Phys Med Rehabil 81(1):110-116.

Chaudhuri K, Healy D, Schapira A, National Institute for Clinical Excellence. 2006. Nonmotor symptoms of Parkinson's disease: Diagnosis and management. Lancet Neurol 5(3):235-245.

Conradsson D, Löfgren N, Ståhle A, Hagströmer M, Franzén E. 2012. A novel conceptual framework for balance training in Parkinson's disease-Study protocol for a randomised controlled trial. BMC Neurol 12:1-11.

Coppin A, Shumway-Cook A, Saczynski J, Patel K, Ble A, Ferrucci L. 2006. Association of executive function and performance of dual-task physical tests among older adults: Analyses from the InChianti study. Age Ageing 35(6):619-624.

Drag L, Bieliauskas L, Kaszniak A, Bohnen N, Glisky E. 2009. Source memory and frontal functioning in Parkinson's disease. J Int Neuropsychol Soc 15(3):399-406.

Ebersbach G, Gunkel M. 2011. Posturography reflects clinical imbalance in Parkinson's disease. Mov Disord 26(2):241-246. 
Elgh E, Domellof M, Linder J, Edstrom M, Stenlund H, Forsgren L. 2009. Cognitive function in early Parkinson's disease: A population-based study. Eur J Neurol 16(12):1278-1284.

Folstein MF, Folstein SE, McHugh PR. 1975. "Mini-mental state". A practical method for grading the cognitive state of patients for the clinician. J Psychiatr Res 12(3):189-198.

Foltynie T, Brayne CEG, Robbins TW, Barker RA. 2004. The cognitive ability of an incident cohort of Parkinson's patients in the UK. The CamPaIGN study. Brain 127(3):550-560.

Goetz CG. 2003. The Unified Parkinson's Disease Rating Scale (UPDRS): Status and recommendations. Mov Disord 18(13):738-750.

Golden C, Espe-Pfeifer P, Wachsler-Felder J. 2000. Neuropsychological interpretations of objective psychological tests. New York: Plenum.

Hoehn MM, Yahr MD. 1967. Parkinsonism: Onset, progression and mortality. Neurology 17(5):427-442. doi:10.1371/journal.pone.0069237

Jamet M, Deviterne D, Gauchard GC, Vançon G, Perrin PP. 2007. Agerelated part taken by attentional cognitive processes in standing postural control in a dual-task context. Gait Posture 25(2):179-184. doi:10.1016/j.gaitpost.2006.03.006

Kelly VE, Eusterbrock AJ, Shumway-Cook A. 2012. A review of dual-task walking deficits in people with Parkinson's disease: Motor and cognitive contributions, mechanisms, and clinical implications. Parkinson's Dis 2012(918719):1-14.

Klepac N, Trkulja V, Relja M, Babic T. 2008. Is quality of life in non-demented Parkinson's disease patients related to cognitive performance? A clinic-based cross-sectional study. Eur J Neurol 15(2):128-133.

Koerts J, Leenders K, Brouwer W. 2009. Cognitive dysfunction in nondemented Parkinson's disease patients: Controlled and automatic behavior. Cortex 45(8):922-929.

Koerts J, Tucha L, Leenders K, Beilen M, Brouwer W, Tucha O. 2011. Subjective and objective assessment of executive functions in Parkinson's disease. J Neurol Sci 310(1-2):172-175.

Lezak MD, Howieson DB, Loring DW. 2004. Neuropsychological assessment. 4th ed. New York: Oxford University Press.

Lim LI, van Wegen EE, de Goede CJ, Jones D, Rochester L, Hetherington V, Nieuwboer A, Willems AM, Kwakkel G. 2005. Measuring gait and gait-related activities in Parkinson's patients' own home environment: A reliability, responsiveness, and feasibility study. Parkinsonism Relat Disord 11:19-24.

Lindholm B, Hagell P, Hansson O, Nilsson M. 2014. Factors associated with fear of falling in people with Parkinson's disease. BMC Neurol 14:19. doi: 10.1186/1471-2377-14-19.

Maetzler M, Bochdansky T, Abboud RJ. 2010. Normal pressure values and repeatability of the Emed ${ }^{\circledR}$ ST2 system. Gait Posture 32(3):391-394.

Marchese R, Bove M, Abbruzzese G. 2003. Effect of cognitive and motor tasks on postural stability in Parkinson's disease: A posturographic study. Mov Disord 18(6):652-658.
Matinolli $M$, Korpelainen JT, Korpelainen R, Sotamiemi KA, Virranniemi $M$, Myllyla VV. 2007. Postural sway and falls in Parkinson's disease: A regression approach. Mov Disord 22(13):1927-1935.

McCloskey G, Perkins L. 2012. Essentials of executive functions assessment. Hoboken, NJ: Wiley.

Merims D, Freedman M. 2008. Cognitive and behavioural in Parkinson's disease. Int Rev Psychiatry 20(4):364-373.

Morgado J, Rocha CS, Maruta C, Guerreiro M, Martins IP. 2009. New normative values of Mini-Mental State Examination. Sinapse 9(2):19-25.

Ostrosky-Solís F, Lozano A. 2006. Digit span: Effect of education and culture. Int J Psychol 41(5):333-341.

Owen A. 2004. Cognitive dysfunction in Parkinson's disease: The role of frontostriatal circuitry. Neuroscientist 10(6):525-537.

Pagonabarraga J, Kulisevsky J. 2012. Cognitive impairment and dementia in Parkinson's disease. Neurobiol Dis 46(3):590-596.

Plotnick M, Giladi N, Hausdorf J. 2009. Bilateral coordination of gait and Parkinson's disease: The effects of dual tasking. J Neurol Neurosurg Psychiatry 80(3):347-350.

Podsiadlo D, Richardson S. 1991. The timed "Up \& Go": A test of basic functional mobility for frail elderly persons. J Am Geriatr Soc 39(2):142-148.

Pringsheim T, Jette N, Frolkis A, Steeves TL. 2014. The prevalence of Parkinson's disease: A systematic review and meta-analysis. Mov Disord 29:1583-1590.

Putti AB, Arnold GP, Cochrane LA, Abboud RJ. 2008. Normal pressure values and repeatability of the Emed ST4 system. Gait Posture 27(3):501-505.

Reitan RM. 1992. Trail Making Test: Manual for administration and scoring. New York: Tuscan.

Sawamoto N, Honda N, Hanakawa T, Fukuyama H, Shibasaki H. 2002. Cognitive slowing in Parkinson's disease: A behavioral evaluation independent of motor slowing. J Neurosci 22(12):5198-5203.

Schwarz GE, Shapiro D. 1986. Consciousness and self-regulation. New York: Plenum Press.

Smithson F, Morris ME, lansek R. 1998. Performance on clinical tests of balance in Parkinson's disease. Phys Ther 78(6):577-592.

Springer S, Giladi N, Peretz C, Yogev G, Simon E, Hausdorff J. 2006. Dualtasking effects on gait variability: The role of aging, falls, and executive functions. Mov Disord 21(7):950-957.

Van-Lersel B, Kessels P, Bloem R, Verbeek A, Rikkert M. 2008. Executive functions are associated with gait and balance in community-living elderly people. J Gerontol A Biol Sci Med Sci 63(12):1344-1349.

Williams-Gray C, Foltynie T, Brayne C, Robbins T, Barker R. 2007. Evolution of cognitive dysfunction in an incident Parkinson's disease cohort. Brain Cogn 130(7):1787-1798.

Wilson BA, Alderman N, Burguess PW, Hazel E, Evans JJ. 2003. Behavioural Assessment of the Dysexecutive Syndrome (BADS). J Occup Psychol Employ Disabil 5(2):33-37. 